\title{
Role of basophils in the pathogenesis of minimal change nephrotic syndrome: A literature review
}

\author{
QINGJUN PAN* , JING WU* , JINGLI TAO, YANWEN CHEN, LU LI, \\ ZHENZHEN DENG, WEIJING LIU and HUAFENG LIU \\ Institute of Nephrology, Affiliated Hospital of Guangdong Medical College, \\ Zhanjiang, Guangdong 524001, P.R. China
}

Received April 23, 2014; Accepted July 21, 2014

DOI: $10.3892 / \mathrm{etm} .2014 .1901$

\begin{abstract}
A number of studies have verified that minimal change nephrotic syndrome (MCNS) may result from the dysfunction of $\mathrm{T}$ cells and $\mathrm{B}$ cells, although the precise mechanisms are yet to be elucidated. It is widely recognized that MCNS is a T helper (Th)2-dominant glomerular disease caused by an imbalanced Th1/Th2 immune response. Increased levels of the Th2 cytokines, interleukin (IL)-4 and IL-13, have been demonstrated to be closely associated with disease activity. In addition, basophils can affect the Th1/Th2 balance by enhancing the Th2 response and impairing the Th1 response, which are then involved in the development of numerous diseases. However, whether basophils are vital in the pathogenesis of MCNS remains unknown. Frequent positivity of the human basophil degranulation test in patients with MCNS has been observed. Thus, basophils should be analyzed in order to determine their role in the pathogenesis of MCNS.
\end{abstract}

\section{Contents}

1. Introduction

2. Imbalance of the Th1/Th2 response and the role in MCNS

3. Role of basophils in the dynamics of Th1/Th2

4. Basophils may be involved in the pathogenesis of MCNS by affecting the dynamic balance of Th1/Th2

5. Mechanisms of basophil activation in patients with MCNS

6. Conclusion

Correspondence to: Professor Huafeng Liu, Institute of Nephrology, Affiliated Hospital of Guangdong Medical College, No. 57 Renmin Avenue (South), Zhanjiang, Guangdong 524001, P.R. China

E-mail: hf-liu@263.net

*Contributed equally

Key words: minimal change nephrotic syndrome, $\mathrm{T}$ helper cell 1, T helper cell 2, basophils, immunoglobulin E, Toll-like receptor

\section{Introduction}

Minimal change nephrotic syndrome (MCNS) is an idiopathic nephrotic syndrome that is common among children. The condition is characterized by detectable, glomerular podocyte foot process fusion without evident kidney lesions, and is defined by proteinuria of $>3.5 \mathrm{~g} /$ day and hypoproteinemia of $<30 \mathrm{~g} / \mathrm{l}$. The levels of edema and hyperlipidemia vary between individuals. MCNS typically occurs in children and is particularly sensitive to corticosteroid treatment, where a short duration of remission and a frequent rate of relapse are often observed (1). However, the mechanisms of MCNS are not fully understood. Certain studies have proposed that MCNS is a T helper (Th)2-dominated disease that may be associated with a circulating factor from MCNS T cells $(2,3)$.

$\mathrm{CD}^{+} \mathrm{T}$ cells are categorized on the basis of their distinct cellular functions and the cytokines secreted. At least two subsets are involved in the development of MCNS: Th1 cells that are characterized by the secretion of interferon- $\gamma$ and tumor necrosis factor- $\beta$, and Th 2 cells that are identified by their secretion of the proinflammatory cytokines, interleukin (IL)-4, IL-5 and IL-13, which are associated with the pathogenesis of immunoglobulin E (IgE) and eosinophilia. Previous studies have indicated that MCNS is associated with atopy (4-7), as well as increased levels of IgE (8-12), IL-13 and IL-4 (13-16).

Basophils are derived from marrow hemopoietic stem cells, and constitute $\leq 1 \%$ of the leukocytes in the peripheral blood (17). Basophils express a high-affinity IgE receptor (FceRl); thus, are associated with IgE-mediated allergic inflammation and innate immunity. Following stimulation, basophil granules release numerous substances, including histamine, heparin and slow-reacting substances of anaphylaxis, which results in the mediation of anticoagulation, the alteration of vascular permeability, the contraction of smooth muscles and hypersensitivity. Previously, the functions of basophils have been developed in vivo and in vitro; with this cell type recognized as the original source of IL-4 and the cause of Th2 polarization induction. However, the precise mechanism underlying the functions of basophils in vivo remains poorly understood.

Therefore, the present study investigated whether an association exists between MCNS and basophils. Possible new perspectives for understanding the role of basophils in the pathogenesis of MCNS were summarized in the present study. 


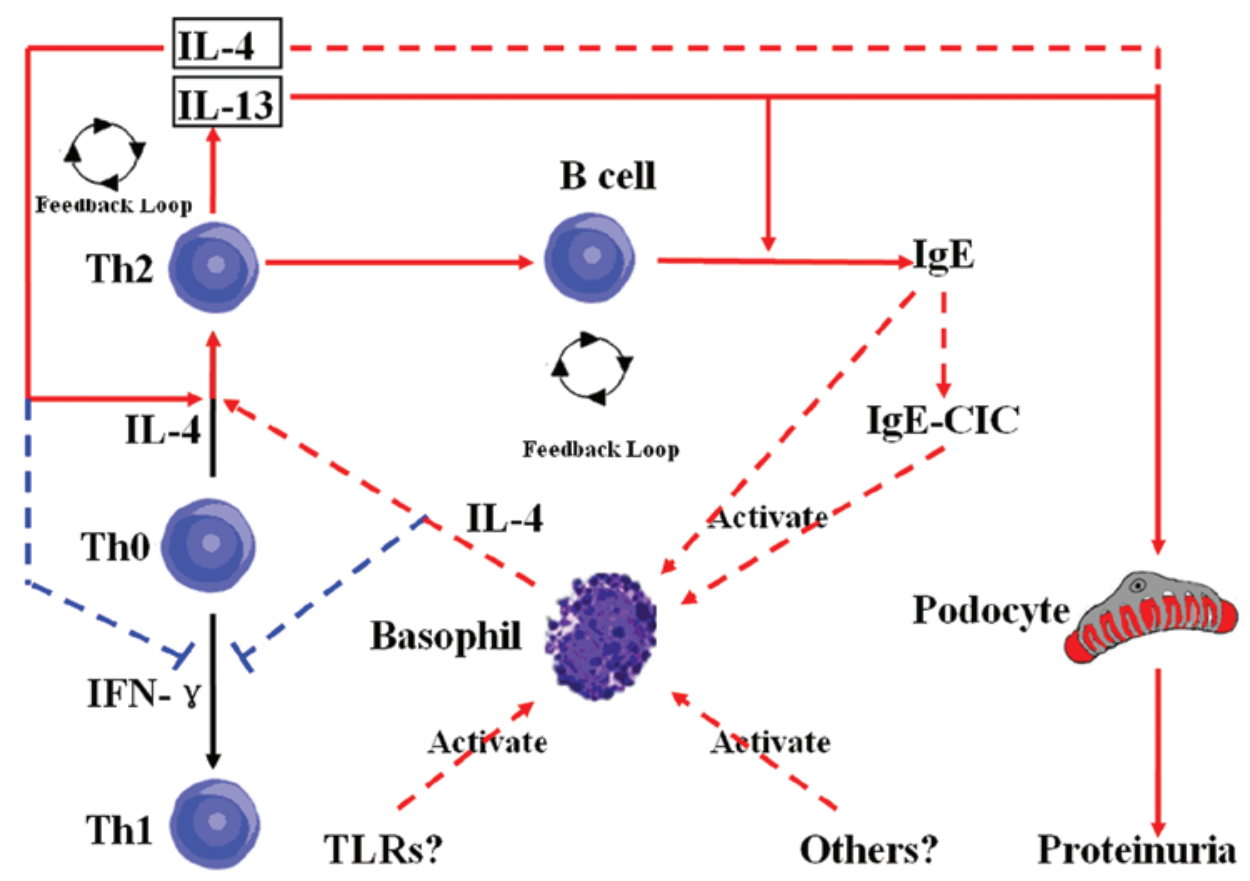

Figure 1. Proposed interactions between basophils, B and T cells in individuals with minimal change nephrotic syndrome (MCNS). The red and black solid lines with arrows represent interactions that have been previously reported, while the red and blue dotted lines with arrows represent interactions that have not been reported in MCNS. The red lines with arrows represent promotional functions and the blue dotted lines with flat heads represent suppressive functions. IL, interleukin; Th, T helper cell; TLR, Toll-like receptor; IFN, interferon; IgE, immunoglobulin E; CIC, circulating immune complexes.

\section{Imbalance of the Th1/Th2 response and the role in MCNS}

The etiology of MCNS is complicated and elusive. Infections and atopy are commonly considered to induce patients with MCNS to relapse in clinics. Increasing evidence has demonstrated that the aberration of $\mathrm{T}$ cells may play a crucial role in the pathogenesis of MCNS, and the importance of T cells in MCNS was first proposed by Shalhoub in 1974 (18). Accordingly, the hygiene hypothesis (19) proposed that MCNS was a Th2-predominant immune response. The balance of the Th1/Th2 response, particularly during childhood development, may be responsible for the later development of specific human glomerulonephritis (GN) (20). A number of studies have observed elevated mRNA expression levels of Th2 cytokines in the peripheral blood leukocytes of MCNS patients (21-24). In addition, a promising but unconfirmed glomerular permeability factor (GPF) from $\mathrm{T}$ cells may be essential to the development of MCNS (25). When this factor was injected intravenously into rats, significant proteinuria was induced and partial fusion of the glomerular epithelial cells was observed via electron microscopy (25). Growth regulated protein (GRO)- $\gamma$ is a potential candidate for the Th2-associated GPF in MCNS, as implicated in the function of endothelial cells. Furthermore, Adrogue et al (26) observed markedly higher levels of $\mathrm{CD}^{+}$ $\mathrm{T}$ cells in patients with MCNS and hypothesized that the levels of IL-4, IL-8 and GRO were also higher in individuals with MCNS. An increase in the level of IL-8 was shown to change the permeability of the glomerular basement membrane (GBM) via reducing the synthesis of heparan sulfate proteoglycans (HSPGs) on the GBM, which eventually induced proteinuria in rats (27). This observation indicated that patients with MCNS tended to develop a Th2-dominant $\mathrm{T}$ cell response.
Receptors for IL-4 and IL-13 are also present in podocytes $(28,29)$, and previous studies have detected higher levels of serum IL-13 and IL-4 in patients with MCNS (13-16). In an animal model, the overexpression of IL-13 induced minimal-change-like nephropathy in rats (30). Furthermore, an additional study demonstrated that IL-13 induced podocyte injury via a signal transducer and activator of transcription-6-dependent pathway in the podocytes of mice (31). Triptolide was able to protect podocytes from IL-13-induced injury in vitro (32). However, the effect of IL-4 on podocyte injury is not well understood and requires further study in the future.

Th2 responses are characterized by IL-4, IL-13 and other Th2 cytokines, which trigger the switch from immunoglobulin M (IgM) to IgE production in B cells. Elevated levels of IL-4 and IL-13 contribute to the progression of Th2-type disease by blocking the differentiation of naive $\mathrm{T}$ cells into Th1 cells. Thus, immune dysregulation plays a crucial role in the pathogenesis of MCNS, although the precise mechanisms remain unclear. Further study concerning the dynamics of the Th1/Th2 response in MCNS may aid the understanding of the disease and be useful for the prevention, treatment and prognosis of MCNS.

\section{Role of basophils in the dynamics of Th1/Th2}

Basophils are primary effector cells involved in IgE-mediated allergic inflammation and innate immunity (33). These cells play distinct roles in allergic inflammatory disease (34); however, further verification of this has remained elusive until recently. Basophils are able to induce the development of $\mathrm{Th} 2$ cells in vitro and in vivo (35), and the depletion of basophils using antibodies against FceRl has been shown to diminish 
the development of Th2 cells (36). Furthermore, following the cross-linking of FceRl-bound IgE by multivalent antigens, basophils can rapidly produce diverse mediators, such as the cytokines IL-4 and IL-13. As basophils are the prime early producers of IL-4, Th2 cytokines, which promote naive CD $4^{+}$ $\mathrm{T}$ cell polarization, trigger the differentiation of Th 2 cells and support humoral memory responses $(37,38)$. Thus, basophils play an essential role in Th2 differentiation from naive $\mathrm{CD} 4^{+}$ T cells, which are also dominant in the pathogenesis of MCNS.

\section{Basophils may be involved in the pathogenesis of MCNS by affecting the dynamic balance of Th1/Th2}

Hypotheses involving basophils in idiopathic nephrotic syndrome (INS) can be traced back to Pirotzky et al in 1982 (39). In the study, the human basophil degranulation test (HBDT), which assumes that the degranulation of basophils in the presence of a specific allergen is an index of an IgE-dependent cellular response, was tested on 46 unselected patients with INS (28 with MCNS and 18 with focal segmental glomerular sclerosis) with or without atopic manifestations. Of the patients with MCNS, 57\% (16/28) had a positive result and were accompanied by basophil activation (39). Laurent et al also observed frequent positivity of the HBDT in individuals with INS (minimal glomerular changes and segmental and focal glomerulosclerosis) (40). Furthermore, Mack and Rosenkranz stated that basophils, which are not frequently studied, should be analyzed when investigating the pathogenesis of MCNS (3).

Based on the evidence that MCNS is a Th2-dominant immune response, basophils, as promoters of the Th2 immune response and crucial sources of IL-4, which may initiate the disease, play an important role in maintaining a Th2-immune response and abating the Th1-immune response, resulting in the aberration of T-cell function. Thus, basophils may be involved in the mechanism of MCNS via affecting the dynamic balance of the Th1/Th2 response (Fig. 1).

\section{Mechanisms of basophil activation in patients with MCNS}

A number of major pathways may be involved in the activation of basophils in MCNS.

IgE-circulating immune complexes (IgE-CIC) mediate basophil activation. Previous studies have demonstrated that serum levels of $\mathrm{IgE}$ are significantly increased in patients with MCNS, and high levels of serum IgE may be associated with poor prognosis $(10,41,42)$. However, IgE or IgE-CIC have not been identified in renal tissue and no experimental models of IgE-mediated nephropathy have, to the best of our knowledge, been reported. Thus, this evidence indicates that the elevated levels of serum IgE observed in MCNS may reflect the abnormal regulation of $\mathrm{IgE}$ synthesis or $\mathrm{B}$ or $\mathrm{T}$ cell activation, which reflects immune dysfunction, but not a role in the pathogenesis of MCNS.

Through the use of a combination of CIC assays, Cairns et al observed CICs in the majority of the 271 serum samples collected from 131 patients with idiopathic MCNS, membranous and mesangial proliferative GN (43). Thus, high serum levels of IgE may mediate basophil activation in individuals with MCNS. Furthermore, autoreactive IgE immune complexes were shown to activate peripheral basophils in a mouse model of lupus nephritis (44). Basophils express the high-affinity IgE receptor, FceRl (45), which cross-links with IgE to activate a series of signaling molecules, including Fyn, Syk, Lyn, phosphoinositide 3-kinase and Akt, which subsequently induces basophil activation and results in the release of inflammatory mediators that are able to mediate tissue injury (46-48). In addition, the levels of a series of surface molecules, including CD203c, CD63 and CD11b, can significantly increase and rapidly produce a large quantity of cytokines, including IL-4 and IL-13. IgE synthesis by B cells requires two signals, one delivered by IL-4 or IL-13, which are released by Th2 cells, and the other via the interaction between the CD40 receptor on B cells and the CD40 ligand expressed by activated $\mathrm{T}$ cells. Activated basophils are able to produce IL-4 and IL-13 and also express the CD40 ligand, through which they are able to interact with B cells. Furthermore, the production of IL-3 by basophils may switch the Ig type towards IgE, which in turn may activate basophils. In this context, autoreactive $\mathrm{IgE}$ and activated basophils may be involved in the pathogenesis of MCNS by affecting the balance of the Th1/Th2 immune response.

Toll-like receptors (TLRs) mediate basophil activation. A number of TLRs are expressed in basophils, including TLR2, TLR4, TLR9 and TLR10 (49). Peptidoglycan is a TLR2 ligand that activates basophils, resulting in the secretion of IL-4 and IL-13, which are independent of nuclear factor- $\kappa$ B activation (50). Basophils can secrete both IL-4 and IL-13 in direct response to peptidoglycan, and peptidoglycan can also augment the secretion of IL-4 and IL-13 in response to IgE-dependent activation, and the secretion of IL-13 in response to IgE-independent stimulation. Furthermore, the inhibition of nuclear factor- $\kappa \mathrm{B}$ does not prevent these enhancing effects mediated by peptidoglycan. TLR4 expressed on basophils may be involved in the pathogenesis of the infection-induced exacerbation of allergic inflammation (49). However, the expression and function of TLR10 in humans and mice is inconsistent and controversial (51).

TLR9 has been found to be expressed in the intracellular compartments of basophils (52). A previous study revealed that TLR9 is involved in the activation of peripheral blood basophils in patients with systemic lupus erythematosus (53). Furthermore, in basophils obtained from patients with MCNS, higher expression levels of TLR9 were identified (data not shown), and KU-812 cells, a basophil cell line, was shown to be activated by TLR9 agonists (53). However, whether TLR9 mediates basophil activation of MCNS in vivo remains unclear. The negative separation of primary human basophils is required for further investigation.

\section{Conclusion}

In conclusion, following the activation of basophils by $\operatorname{IgE}$ complexes or TLRs, various mediators, including IL-4, IL-8, IL-13 and regulated on activation, normal T cell expressed and secreted protein, are released (54). These mediators promote the differentiation of naive Th cells by Th2 and 
may be involved in the pathogenesis of MCNS (55). Based on this evidence, the study of basophils in patients with MCNS may provide novel perspectives on the pathogenesis of the disease.

\section{Acknowledgements}

The study was supported by grants from Natural Science Foundation of China (no. 81202346), the Natural Science Foundation of Guangdong Province, China (no. S2012040006216), Zhanjiang Planning Project of Science and Technology (nos. 2012C3101028 and 2013B01086), the Medical Scientific Research Foundation of Guangdong Province, China (no. B2012284) and the Doctoral Fund of Guangdong Medical College and the Affiliated Hospital of Guangdong Medical College.

\section{References}

1. Hodson EM, Knight JF, Willis NS and Craig JC: Corticosteroid therapy for nephrotic syndrome in children. Cochrane Database Syst Rev 2: CD001533, 2004.

2. Hardwicke J, Soothill JF, Squire JR and Holti G: Nephrotic syndrome with pollen hypersensitivity. Lancet 1: 500-502, 1959.

3. Mack M and Rosenkranz AR: Basophils and mast cells in renal injury. Kidney Int 76: 1142-1147, 2009.

4. Lagrue G and Laurent J: Allergy and lipoid nephrosis. Adv Nephrol Necker Hosp 12: 151-175, 1983.

5. Reeves WG, Cameron JS, Johansson SG, et al: Seasonal nephrotic syndrome. Description and immunological findings. Clin Allergy 5: 121-137, 1975.

6. Laqrue $\mathrm{G}$ and Laurent J: Nephrotic syndrome and hypersensitivity to pollens (author's transl). Nouv Presse Med 11: 1479-1481, 1982 (In French).

7. Rytand DA: Onset of the nephrotic syndrome during a reaction to bee sting. Stanford Med Bull 13: 224-233, 1955.

8. Schulte-Wisserman H, Görtz W and Straub E: IgE in patients with glomerulonephritis and minimal-change nephrotic syndrome. Eur J Pediatr 131: 105-111, 1979.

9. Chan MK, Chan KW and Jones B: Immunoglobulins (IgG, IgA, $\operatorname{IgM}, \operatorname{IgE})$ and complement components $(\mathrm{C} 3, \mathrm{C} 4)$ in nephrotic syndrome due to minimal change and other forms of glomerulonephritis, a clue for steroid therapy? Nephron 47: 125-130, 1987.

10. Shu KH, Lian JD, Yang YF, et al: Serum IgE in primary glomerular diseases and its clinical significance. Nephron 49: 24-28, 1988.

11. Reeves WG, Cameron JS and Ogg CS: IgE and the nephrotic syndrome. Lancet 1: 1299-1300, 1971.

12. Yokoyama H, Kida H, Tani Y, et al: Immunodynamics of minimal change nephrotic syndrome in adults $\mathrm{T}$ and $\mathrm{B}$ lymphocyte subsets and serum immunoglobulin levels. Clin Exp Immunol 61 : 601-607, 1985.

13. Kang J, Bai KM, Wang BL, et al: Increased production of interleukin 4 in children with simple idiopathic nephrotic syndrome Chin Med J (Engl) 107: 347-350, 1994.

14. Cho BS, Yoon SR, Jang JY, et al: Up-regulation of interleukin-4 and CD23/FcepsilonRII in minimal change nephrotic syndrome. Pediatr Nephrol 13: 199-204, 1999.

15. Lama G, Luong I, Tirino G, et al: T-lymphocyte populations and cytokines in childhood nephrotic syndrome. Am J Kidney Dis 39: 958-965, 2002.

16. Gong WK, Cheung W and Yap HK: Minimal change nephrotic syndrome - a complex genetic disorder. Ann Acad Med Singapore 29: 351-356, 2000.

17. Falcone FH, Zillikens D and Gibbs BF: The 21st century renaissance of the basophil? Current insights into its role in allergic responses and innate immunity. Exp Dermatol 15: 855-864, 2006.

18. Shalhoub RJ: Pathogenesis of lipoid nephrosis: a disorder of T-cell function. Lancet 2: 556-560, 1974.

19. Okada H, Kuhn C, Feillet H and Bach JF: The 'hygiene hypothesis' for autoimmune and allergic diseases: an update. Clin Exp Immunol 160: 1-9, 2010.
20. Hurtado A and Johnson RJ: Hygiene hypothesis and prevalence of glomerulonephritis. Kidney Int Suppl 97: S62-S67, 2005.

21. Masutani K, Taniguchi M, Nakashima H, Yotsueda H, et al: Up-regulated interleukin-4 production by peripheral T-helper cells in idiopathic membranous nephropathy. Nephrol Dial Transplant 19: 580-586, 2004.

22. Shimoyama H, Nakajima M, Naka H, Maruhashi Y, et al: Up-regulation of interleukin-2 mRNA in children with idiopathic nephrotic syndrome. Pediatr Nephrol 19: 1115-1121, 2004.

23. Yap HK, Cheung W, Murugasu B, et al: Th1 and Th2 cytokine mRNA profiles in childhood nephrotic syndrome: evidence for increased IL-13 mRNA expression in relapse. J Am Soc Nephrol 10: 529-537, 1999.

24. Lama G, Luongo I, Tirino G, Borriello A, et al: T-lymphocyte populations and cytokines in childhood nephrotic syndrome. Am J Kidney Dis 39: 958-965, 2002.

25. Koyama A, Fujisaki M, Kobayashi M, et al: A glomerular permeability factor produced by human $\mathrm{T}$ cell hybridomas. Kidney Int 40: 453-460, 1991.

26. Adrogue HE, Borillo J, Torres L, et al: Coincident activation of $\mathrm{Th} 2 \mathrm{~T}$ cells with onset of the disease and differential expression of GRO-gamma in peripheral blood leukocytes in minimal change disease. Am J Nephrol 27: 253-261, 2007.

27. Cho MH, Lee HS, Choe BH, et al: Interleukin-8 and tumor necrosis factor-alpha are increased in minimal change disease but do not alter albumin permeability. Am J Nephrol 23: 260-266, 2003.

28. Parry RG, Gillespie KM, Parnham A, et al: Interleukin-4 and interleukin-4 receptor polymorphisms in minimal change nephropathy. Clin Sci (Lond) 96: 665-668, 1999.

29. Abdel-Hafez M, Shimada M, Lee PY, et al: Idiopathic nephrotic syndrome and atopy: is there a common link? Am J Kidney Dis 54: 945-953, 2009.

30. Lai KW, Wei CL, Tan LK, Tan PH, et al: Overexpression of interleukin-13 induces minimal-change-like nephropathy in rats. J Am Soc Nephrol 18: 1476-1485, 2007.

31. Hong YM, Liu ZH, Chen ZH, et al: Interleukin-13 induced podocyte injury via a signal transducer and activator of transcription-6-dependent way. Shen Zang Bing Yu Tou Xi Shen Yi Zhi Za Zhi 18: 140-147, 2009 (In Chinese).

32. Tang TF, Hong YM, Chen ZH, et al: Triptolide protects podocytes from IL-13 induced injury in vitro. Yi Xue Yan Jiu Sheng Bao 23: 1140-1144, 2010 (In Chinese).

33. Pan QJ, Liu Y and Fu N: Progress of research on basophils in allergic and immune reactions. Zhongguo Mian Yi Xue Za Zhi 25: 671-673, 2009 (In Chinese).

34. Karasuyama H, Mukai K, Tsujimura Y and Obata K: Newly discovered roles for basophils: a neglected minority gains new respect. Nat Rev Immunol 9: 9-13, 2009.

35. Yoshimoto T, Yasuda K, Tanaka H, Nakahira M, et al: Basophils contribute to $\mathrm{T}(\mathrm{H}) 2$-IgE responses in vivo via IL-4 production and presentation of peptide-MHC class II complexes to $\mathrm{CD}^{+}$ T cells. Nat Immunol 10: 706-712, 2009.

36. Sokol CL, Barton GM, Farr AG and Medzhitov R: A mechanism for the initiation of allergen-induced $\mathrm{T}$ helper type 2 responses. Nat Immunol 9: 310-318, 2008.

37. Kasaian MT, Clay MJ, Happ MP, Garman RD, et al: IL-4 production by allergen-stimulated primary cultures: identification of basophils as the major IL-4-producing cell type. Int Immunol 8: 1287-1297, 1996.

38. Charles N, Watford WT, Ramos HL, et al: Lyn kinase controls basophil GATA-3 transcription factor expression and induction of Th2 cell differentiation. Immunity 30: 533-543, 2009.

39. Pirotzky E, Hieblot C, Benveniste J, Laurent J, Lagrue G and Noirot C: Basophil sensitisation in idiopathic nephrotic syndrome. Lancet 1: 358-361, 1982.

40. Laurent J, Lagrue G, Pirotzky E, Hirbec G, Hieblot C and Benveniste J: Frequent positivity of the human basophil degranulation test in idiopathic nephrotic syndromes (minimal glomerular changes and segmental and focal glomerulosclerosis). Nephrologie 5: 9-14, 1984 (In French).

41. Tan Y, Yang D, Fan J and Chen Y: Elevated levels of immunoglobulin $\mathrm{E}$ may indicate steroid resistance or relapse in adult primary nephrotic syndrome, especially in minimal change nephrotic syndrome. J Int Med Res 39: 2307-2313, 2011.

42. Fuke Y, Endo M, Ohsawa I, Satomura A, et al: Implication of elevated serum IgE levels in minimal change nephrotic syndrome. Nephron 91: 769-770, 2002.

43. Cairns SA, London RA and Mallick NP: Circulating immune complexes in idiopathic glomerular disease. Kidney Int 21: 507-512, 1982 . 
44. Charles N, Hardwick D, Daugas E, et al: Basophils and the $\mathrm{T}$ helper 2 environment can promote the development of lupus nephritis. Nat Med 16: 701-707, 2010.

45. Buschor P, Eggel A, Zellweger F, Stadler BM and Vogel M: Improved Fc $\gamma$ RIIb targeting functionally translates into enhanced inhibition of basophil activation. Int Arch Allergy Immunol 163: 206-214, 2014.

46. MacGlashan D Jr: IgE receptor and signal transduction in mast cells and basophils. Curr Opin Immunol 20: 717-723, 2008.

47. MacGlashan DW Jr: Self-termination/anergic mechanisms in human basophils and mast cells. Int Arch Allergy Immunol 150: 109-121, 2009

48. Gilfillan AM, Peavy RD and Metcalfe DD: Amplification mechanisms for the enhancement of antigen-mediated mast cell activation. Immunol Res 43: 15-24, 2009.

49. Komiya A, Nagase H, Okugawa S, et al: Expression and function of Toll-like receptors in human basophils. Int Arch Allergy Immunol 140 (Suppl 1): 23-27, 2006.

50. Bieneman AP, Chichester KL, Chen YH and Schroeder JT: Toll-like receptor 2 ligands activate human basophils for both IgE-dependent and IgE-independent secretion. J Allergy Clin Immunol 115: 295-301, 2005.
51. Takeda $\mathrm{K}$ and Akira S: Toll-like receptors in innate immunity. Int Immunol 17: 1-14, 2005.

52. Creticos PS,SchroederJT,Hamilton RG,Balcer-Whaley SL, etal: Immunotherapy with a ragweed-Toll-like receptor 9 agonist caccine for allergic rhinitis. N Engl J Med 355: 1445-1455, 2006.

53. Pan Q, Wang G, Ye L, Feng Y, Wang C and Liu H: Toll-like receptor 9 is involved in the activation of peripheral blood basophils of patients with systemic lupus erythematosus. Clin Exp Allergy 42: 1821-1822, 2012.

54. Sabroe I, Jones EC, Usher LR, et al: Toll-like receptor (TLR)2 and TLR4 in human peripheral blood granulocytes: a critical role for monocytes in leukocyte lipopolysaccharide responses. J Immunol 168: 4701-4710, 2002.

55. Suurmond J, Stoop JN, Rivellese F, Bakker AM, et al: Activation of human basophils by combined Toll-like receptor- and FceRI-triggering can promote Th2 skewing of naive T helper cells. Eur J Immunol 44: 386-396, 2014. 